\title{
UNUSUAL ABDOMINAL TUMORS WITH INTRACARDIAC EXTENSION. TWO CASES WITH SUCCESSFUL SURGICAL RESECTION
}

\author{
Noedir A. G. Stolf, Gilmar Geraldo dos Santos and Victor L. S. Haddad
}

\begin{abstract}
STOLF, NAG et al. - Unusual abdominal tumors with intracardiac extension. Two cases with successful surgical resection. Rev Hosp. Clín. Fac. Med. S. Paulo 54 (5):159-164;1999.

SUMMARY: Abdominal tumors that can grow through vascular lumen and spread to the right heart are rare. Although these tumors have different histologic aspects, they may cause similar abdominal and cardiac symptoms and are a serious risk factor for pulmonary embolism and sudden death when they reach the right atrium and tricuspid valve. The best treatment is radical surgical resection of the entire tumor using cardiopulmonary bypass with or without deep hypothermia and total circulatory arrest. We report the cases of two patients, the first with leiomyosarcoma of the inferior vena cava and the other with intravenous leiomyomatosis of the uterus that showed intravascular growth up to right atrium and ventricle, who underwent successful radical resection in a one-stage procedure with the use of cardiopulmonary bypass. We discuss the clinical and histologic aspects and imaging diagnosis and review the literature.
\end{abstract}

DESCRIPTORS: Intracardiac tumor. Vena cava neoplasms. Heart neoplasms. Surgical procedure.

Abdominal tumors with intravascular growth and cardiac involvement are rare. Of abdominal tumors that can grow in the lumen of the inferior vena cava (IVC) up to the right heart the most frequent are renal carcinomas ${ }^{1,2}$, intravenous leiomyomatosis of the uterus (IVL) ${ }^{3,4}$, and leiomyosarcoma of the IVC ${ }^{5}$.

Leiomyosarcomas (LMS) are rare malignant mesenchymal tumors originating in the smooth muscles of the vessels and were first reported by Perl ${ }^{6}$ in 1871. It has been more often described in the last 15 years and, up to now, 215 cases have been reported. Intravascular growth spreading to the right heart chambers was found in 40 patients, about $18.6 \%$ of all cases, and of those, only nine underwent surgical treatment.

Intravenous leiomyomatosis is a rare uterine neoplasm, reported by Birsh-Hirshfeld in $1896^{7}$ and Knauer in $1903^{8}$, and is characterized by nodular masses of histologically benign smooth muscle and intraluminal growth that may extend variable distances.

We herein report the case of two patients successfully treated through radical surgical resection of intracardiac tumors of abdominal origin using cardiopulmonary bypass (CPB) - normothermic in the first case and total circulatory arrest and deep hypothermia in the other- with complete removal of the primary site and its extension in a one-stage procedure.

\section{CASE REPORTS}

Case 1.: A 41-year-old White man was admitted with progressive dyspnea, orthopnea and paroxysmal

From INCOR, University of São Paulo School of Medicine, São Paulo - Brazil and the Unit of Thoracic Illness - Beneficiência Portuguesa Hospital, São Paulo - Brazil. nocturnal dyspnea, and palpitations of four months duration. A previous history of venous thromboses of the lower limbs was found, diagnosed one year previously. Recently, edema of the lower limbs and mild peripheral cyanoses was noted. He was receiving Digoxin and Furosemide. Physical examination showed severe congestive heart failure, mild peripheral cyanoses and jaundice. No heart murmur was found. The abdomen was globus, with remarkable ascites. The liver was enlarged about $12 \mathrm{~cm}$. and quite painful. No abdominal mass was found. Functionally, he was in class IV of NYHA. Echocardiogram, Computerized tomography and magnetic resonance imaging showed a tumor in the IVC, which was partially occluded, and the tumor was propagating into the right atrium. The patient underwent surgery on December $9^{\text {th }} 1992$ through a median anterior sternotomy extending to the abdomen. Normothermic 
cardiopulmonary bypass (CPB) was accomplished with venous cannulas in the superior vena cava and left femoral vein and the arterial line in the ascending aorta, which was left unclamped. A large tumoral mass was found in the right atrium extending into the right ventricle (Fig. 1), IVC, and suprahepatic veins, which were partially occluded. The intracardiac and upper segments of the tumor were resected. The IVC was opened below the liver, and the tumor origin was found in the middle segment of this vein, extending towards the renal veins. The tumor was completely removed (Fig. 2). The IVC was closed with a direct running suture. Diffuse bleeding remained and was controlled with difficulty. The tumor was a multi-lobulated grayreddish mass, $36 \mathrm{~cm}$. in length and five to eight $\mathrm{cm}$. in diameter. The patient had a problematic immediate postoperative period with low cardiac output, respiratory and renal failure, rises in hepatic enzymes, and jaundice. Subsequently, he had a good recovery and was discharged in the $28^{\text {th }}$ postoperative day, functionally NYHA class I. $\mathrm{He}$ remained well, but in spite of receiving chemotherapy, he died of diffuse abdominal metastases 24 months after surgery.

Case 2.: A.M., a 43 year-old white woman, with three previous pregnancies and deliveries, was admitted with progressive dyspnea, orthopnea, paroxysmal nocturnal dyspnea and palpitations. She denied weight loss and gynecologic symptoms. Physical examination revealed jugular stasis, sinus rhythm, and a grade $3 / 6$ systolic murmur (at the third and fourth intercostal space on the left sternal border. There was neither palpable abdominal mass nor peripheral edema. The chest $\mathrm{x}$-ray showed moderate right atrial and ventricular enlargement. No abnormality was found in the electrocardiogram. An echocardiogram

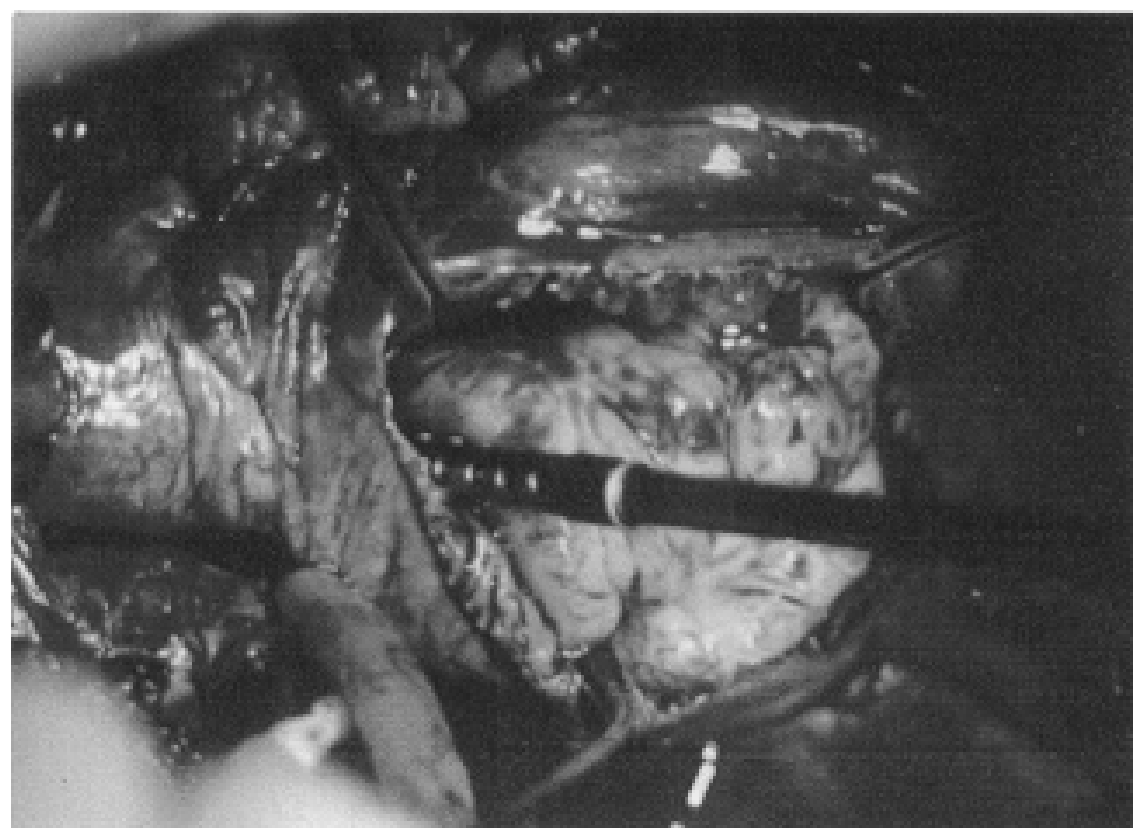

Figure 1 - Leiomyosarcoma of the IVC in the right atrium.

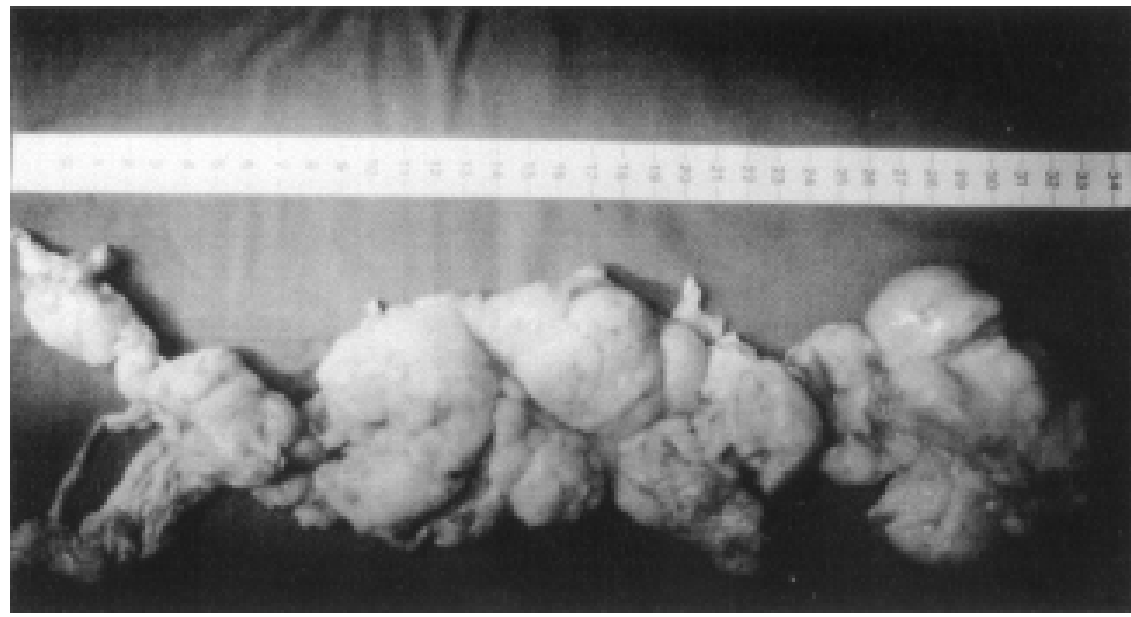

Figure 2 - Leiomyosarcoma of the IVC after resection.

revealed during diastole an intracardiac tumor arising from the IVC and moving from the right atrium into right ventricle through the tricuspid valve. Computed tomography and magnetic resonance confirmed the presence of a tumor in the IVC and right atrium. The diagnosis of a tumor of the IVC was made.

The patient underwent surgery on December $7^{\text {th }}, 1994$. A median thoracoabdominal incision was made exposing the heart and infra-hepatic vena cava, and a CPB was performed with a single venous cannula, hypothermia to $16^{\circ} \mathrm{C}$, and total circulatory arrest. The right atrium was opened, and a large mass arising from the IVC and propagating to the right ventricle and pulmonary artery was found, free of adhesions. The thoracic part of the tumor was resected. There was no abnormality of the tricuspid valve. The IVC was incised, and the abdominal portion of the tumor arising from the right ovarian vein was found with no adhesions to the wall; it was removed. After closing the IVC and right atrium incisions, the patient was rewarmed and the $\mathrm{CPB}$ discontinued. 


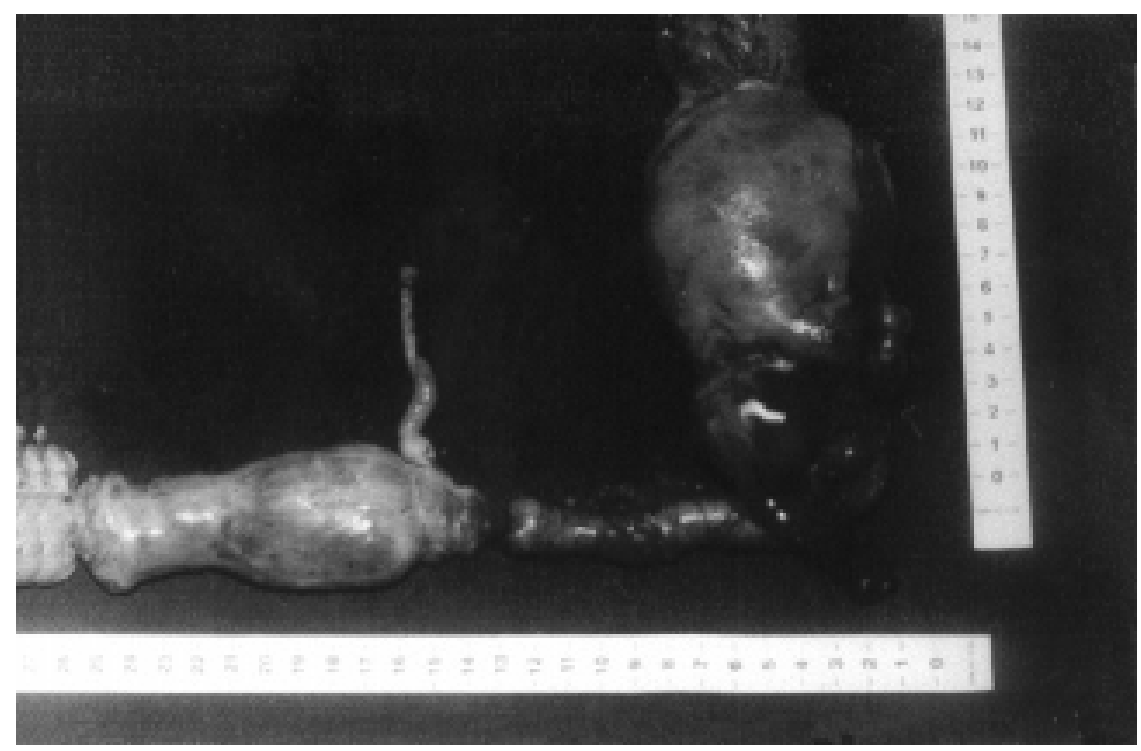

Figure 3 - Intravenous Leiomyomatosis of the uterus after resection.

The time of $\mathrm{CPB}$ was 84 minutes and circulatory arrest 10 minutes. After closing the thoracic incision, a total hysterectomy and bilateral adnexectomy was performed removing the primary site of the tumor and the right ovarian vein. The tumor was a firm; gray-reddish, worm-like mass $25.0 \mathrm{~cm}$ in length, with a diameter varying from 1.0 to $4.0 \mathrm{~cm}$ and a weight of $120 \mathrm{~g}$. (Fig. 3). Pathologic examination revealed the uterus to be $400 \mathrm{~g}$ in weight, 8.0 $\mathrm{cm}$ in length, and $3.0 \mathrm{~cm}$ in thickness. There were 2 intramural, well-delimited nodules of 1.5 and $3.0 \mathrm{~cm}$ characterized by interlaced bundles of smooth muscle fibers. Beside the left adnexa, a tumor was found that was 9 $\mathrm{cm}$ in length and $3 \mathrm{~cm}$ in diameter, was firm, multinodular, gray, worm-like, and had hemorrhagic areas, similar to the tumor in the IVC. The Endometrium and adnexa were normal.

Microscopic examination showed uterine leiomyoma with elongated smooth muscle fibers, nuclear pleomorphism and hyperchromatism, slight atypia and mitotic activity, and invasion of blood vessels. The diagnosis was neoplasm of undefined malig- nancy, borderline for leiomyosarcoma and cellular leiomyoma.

The postoperative outcome was uneventful and the patient was discharged on the $13^{\text {th }}$ postoperative day. She remains asymptomatic after 56 months.

\section{DISCUSSION}

Of the abdominal tumors that grow in the lumen of the IVC propagating into the heart, the most frequent are renal carcinomas and have been found in 0.7 to $1 \%$ of cases. ${ }^{1,2}$ Intravenous leiomyomatosis of the uterus (IVL) is rare, and about $10 \%$ spread to the heart. ${ }^{3,4}$. Leiomyosarcoma (LMS) of the IVC with cardiac involvement was found in 40 out of 215 cases reported (18.6\%).

Primary vascular LMS are rare malignant tumors originating from the media of the vessel wall. They are found five times more often in large veins than in arteries, and the IVC is most frequently involved ${ }^{9}$. The incidence of LMS of IVC was 2 in $14.000^{10}$ in post-mortem examinations.
Leiomyosarcoma of the IVC is found in adults from 15 to 83 years old, mostly in the $6^{\text {th }}$ decade and in females at a 6:1 ratio. Their length varies from 5 to $38 \mathrm{~cm}$, and they weigh up to 3.6 $\mathrm{kg}$. They present generally as firm, multi-lobulated and gray-reddish masses. Histologically, they have large and hyperchromatic nuclei with great number of mitoses ${ }^{5,11}$. Tumors that arise from the inferior segment of the IVC often grow slowly into adjacent tissue and spread mainly to the kidneys, liver, and aorta in the late stage of the disease. Tumors from the middle and upper segment tend to expand intraluminally, leading to partial, and rarely to total, occlusion of the vascular lumen. The most frequent origin of the tumor is in the middle segment of the IVC (47\%), followed by inferior $(32 \%)$ and superior $(21 \%)$ segments. Metastases are found in $44 \%$ of patients at first observation, most frequently to the liver (42\%) and lung $(31 \%)^{5,11}$.

Intravenous leiomyomatosis was first described by Birch-Hirschfeld in $1896^{7}$ and defined by Norris and Parmley in $1975^{12}$. It is a rare neoplasm, characterized by intraluminal growth of benign smooth muscle cell tumor in either venous or lymphatic vessels, that may sometimes spread into inferior vena cava and right cardiac cavities. It is almost exclusively found in women, with the majority of the tumors originating from the uterus. Exceptional cases were found originating from vessels of the skin, IVC, pelvic, or retroperitoneal veins ${ }^{12,13}$.

Histologically, they look like a benign neoplasm, with smooth muscle cells around and invading vessels, variable amounts of fibrosis and hyaline degenerations, slight or absence of nuclear atypia and pleomorphism, little mitotic activity, and moderate cellularity, as well bizarre multinuclear and giant cells ${ }^{12}$. When increased cellulari- 
ty, mitotic activity, and nuclear pleomorphism are observed, the diagnosis of smooth muscle tumor of uncertain malignant potential ${ }^{13}$ can be made, as in the present report.

About $90 \%$ of the patients reported have been parous, and $10 \%$ have had a history of previous hysterectomy or pelvic surgery ${ }^{3}$. The IVL extension to the heart was first reported by Dürk ${ }^{14}$ in 1907. Open heart surgery was first reported by Mandelbaum et al. ${ }^{15}$ in 1974. Up to now, 32 cases have been reported.

These tumors present similar clinical findings according to their sites. They can be asymptomatic and found accidentally in abdominal ultrasonography, unrelated operations and necropsy. Abdominal pain is the main complaint found in $68 \%$ of the patients, often misdiagnosed as biliary pain. Other findings are nausea, emesis, fever, weakness, anorexia, jaundice, pallor, dyspnea, and weight loss. The tumor mass in the right atrium and ventricle with intermittent partial obstruction of the tricuspid valve leads to symptoms of dyspnea, palpitation, dizziness, syncope, congestive heart failure with hepatomegaly, ascites, jugular stasis, and peripheral edema, arrhythmias and pulmonary embolism $4,5,11,16$. Further growth of the tumor can worsen the clinical course and increase the risk of sudden death due to total obstruction of the tricuspid valve ${ }^{17-23}$. Tumor and thrombi in the upper segment of IVC lead to Budd-Chiari syndrome and edema of lower extremities $4,5,11,16,24$

The bi-dimensional echocardiogram ${ }^{25}$ with emphasis on transesophageal orientation, computed tomography, and magnetic resonance can be used to confirm the diagnosis. Magnetic resonance has been found to be superior to computed tomography in determining the intravascular nature of the tumor and its extension 16,26. Additional information can be disclosed by venacavogram and ultrasonography in a search for metastasis in the abdominal cavity.

The patient status, absence of demonstrable metastases, possibility of resection of the entire tumor, and the risk of sudden death and pulmonary embolism indicate immediate surgical treatment. Early surgical treatment with radical and extensive resection has proven to have the best mid- and long-term results. ${ }^{5,11,16}$. Tumors of IVC can be resected using venous-venous bypass and $\mathrm{CPB}$ with normothermia or profound hypothermia and circulatory arrest $16,27,28$. The Pringle maneuver may provide a bloodless field while removing the tumor and thrombus ${ }^{28}$. Reconstruction of the IVC can be done through venography or patch angioplasty ${ }^{5,16}$, biological tissue, or with graft replacement with synthetic tube of polytetrafluorethylene (PTFE) ${ }^{27,29}$, which gives better results. Translocation of a segment of the IVC has been proposed and the "en-bloc" resection of the IVC and the adjacent aorta have been used in order to achieve a wider safety margin and decrease the possibility of local recurrence. Profound hypothermia and total circulatory arrest, reported by Krane et. al. ${ }^{2}$ and Marshall et al. ${ }^{30}$ can be used to some advantage, such as providing a clear and bloodless operative field, better tumor management, minor risk of embolization, and prevention of uncontrollable hemorrhage. It also obviates the need of ligation of collateral vessels, occlusion of porta hepatis, and aortic cross-clamping, and reduces total blood loss. The disadvantage is the coagulopathy induced by deep hypothermia.

Recurrence of LMS of the IVC after radical resection was found in $38.5 \%{ }^{4,11,16}$ of the patients, and may occur for the IVL even after hysterectomy and bilateral adnexectomy evidencing that the tumor growth is independent of the presence of the uterus, and although histologically benign, might be malignant in its mode of behavior ${ }^{31}$. The long term survival rates for surgically treated patients was $27.9 \%$ and $14.2 \%$ after five and ten years, respectively. Tumors of the upper segment are often inoperable and have the worst prognosis ${ }^{5,11}$.

Adjuvant therapies, such as radiotherapy and chemotherapy, have been administered without a well established protocol. With the use of different agents, dose, and duration of administration, it becomes difficult to evaluate the impact of treatment. Given preoperatively, radiotherapy and chemotherapy may control micrometastasis, reduce the size of the tumor, prevent progression, and delay recurrence. However, this therapy has failed to improve the long term survival rate $^{16}$.

In conclusion, abdominal tumors with extension into the heart are often misdiagnosed as primary cardiac disease because of several similar clinical manifestations, and produce a high risk of death when they reach the tricuspid valve. Early surgical treatment with radical resection is advised due to the high risk of pulmonary embolism, arrhythmia, and sudden death, high malignance and poor prognosis. Efficient adjuvant therapy is to be established. This report demonstrates that, since the patients who underwent surgery were in extreme poor condition, the operation prolonged survival and improved their quality of life. Careful follow up lasting several years is required because of the possibility of recurrence. 
STOLF, NAG et al. - Tumores abdominais raros com crescimento intracardíaco. A propósito de dois casos operados com sucesso. Rev. Hosp. Clín. Fac. Med. S. Paulo 54 (5): 159-164;1999.

Tumores abdominais que crescem pela luz dos vasos e atingem o coração são raros. Estes tumores possuem características histológicas distintas porém causam sintomas abdominais e cardíacos semelhantes e apresentam elevado risco de embolia pulmonar e morte súbita quando atingem o átrio direito e a valva tricúspide. O tratamento mais eficaz é a ressecção cirúrgica radical de todo o tumor usandose circulação extracorpórea com ou sem hipotermia profunda e parada circulatória total. Relatamos os casos de dois pacientes, o primeiro portador de leiomiossarcoma primário da veia cava inferior e o segundo com leiomiomatose intravascular uterina com crescimento pela veia cava inferior alcançando o átrio e ventrículo direitos, que foram operados com sucesso para ressecção concomitante do tumor primário e de sua extensão intracardíaca, com auxílio da circulação extracorpórea. Os aspectos clínicos, laboratoriais e histopatológicos são discutidos e é feita revisão da literatura.

DESCRITORES: Tumor intracardíaco. Neoplasia da veia cava inferior. Procedimento cirúrgico.

\section{REFERENCES}

1. NOVICK AC \& COSGROVE DM - Surgical approach for removal of renal cell carcinoma extending into the vena cava and the right atrium. J Urol 1980; 123:947.

2. KRANE RJ, DE VERE WHITE R, DAVIS E et al. - Removal of renal cell carcinoma extending into the right atrium using cardiopulmonary bypass, profound hypothermia and circulatory arrest. J Urol 1984; 131:945.

3. TO WWK, NGAN HYS \& COLLINS RJ - Intravenous leiomyomatosis with intracardiac involvement. Int J Gynaecol Obstet 1993; 42:37.

4. CLEVELAND DC, WESTABY S \& KARP RB - Treatment of intraatrial cardiac tumors. JAMA 1983; 249:2799.

5. MINGOLI A, FELDHAUS JR, CAVALLARO A et al. - Leiomyosarcoma of the inferior vena cava: Analysis and search of world literature on 141 patients and report of three new cases. J Vasc Surg 1991;14:688-99.

6. PERL L - Ein Fall von Sarkom de V cava inferior. Virchows Arch Pathol Anat 1871;53: 378-83.

7. BIRSH-HIRSHFELD FV - Lehbuch der pathologishen anatomie. $5^{\text {th }}$ ed. Leipzig, FCW Vogel, 1896

8. KNAUER E - Beitrag zur Anatomie der Uterusmyome. Beitr Geburtshilfe Gynaekol 1903; 1:695.

9. KERVOKIAN J \& CENTO DP - Leiomyosarcoma of large arteries and veins. Surgery 1973; 73: 390-400.

10. ABELL MR - Leiomyosarcoma of the inferior vena cava. Review of the literature. Report of two cases. Am J Clin Pathol 1957; 28: 272-87.

11. CACOUB P, PIETTE JC, WECHSLER B et al. - Leiomyosarcoma of the Inferior Vena Cava. Experience with 7 patients and Literature Review. Medicine-Baltimore 1991; 70:293-306.

12. NORRIS HJ \& PARMLEY T - Mesenchymal tumors of the uterus: Intravenous leiomyomatosis clinical and pathologic study of 14 cases. CANCER 1975; 36:2164

13. GROVE A \& JØRGENSEN A - Intravascular Leiomyomatosis of the Uterus. Path Res Pract 1996; 192:949-56.

14. DÜRK H - Ueber ein kontinvierlich durch die entere Hohlvene in das Herz vorwachsendes. Fibroma des Uterus. MMW 1907; 54:1154.
15. MANDELBAUM I, PAULETTO FJ \& NASSER WK - Resection of a leiomyoma of the inferior vena cava that produced tricuspid valvular obstruction . J Thoracic Cardiovasc Surg 1974; 67:561-567.

16. KULAYLAT MN, KARAKOUSIS CP, DOERR RJ et al. - Leiomyosarcoma of the Inferior vena cava: A Clinicopathologic review and report of three cases. J Surg Oncol 1997; 65: 205-217.

17. HOFFBRAND AV \& LLOID THG - Leiomyosarcoma of the inferior vena cava leading to obstruction of the tricuspid valve. Br Heart $\mathbf{J}$ 1964; 26: 709-15.

18. GUTIEREZ O, DESAI S \& BURGENER F - Leiomyosarcoma of the inferior vena cava with intracardiac extension. Europ J Radiol 1986; 6: 153-55.

19. DEUTSCH V, FRAENKEL O \& FREUND U - Leiomyosarcoma of the inferior vena cava propagating into the right atrium. Br Heart J 1968; 30: 571-74.

20. DEMOULIN JC, SAMBONY, BOUDIOETY et al. - Leiomyosarcoma of the inferior vena cava. An unusual cause of pulmonary embolism. Chest 1974; 66: 597-99.

21. WILMSHUST P - Leiomyosarcoma in the right atrium and occluding the inferior vena cava. Br Heart J 1995; 73(3): 236.

22. NILI M, LIBAN E \& LEVY MJ - Tricuspid stenosis due to intravenous leiomyomatosis - a call for caution: case report e review of the literature. Texas Heart Inst J 1982; 9:231-5.

23. GONZALEZ-LAVIN L, LEE RH, FALK L et al. - Tricuspid valve obstruction due to intravenous leiomyomatosis. Am Heart J 1984; 108: 1544-6.

24. MONIG SP, GAWENDA M, ERASMI H et al. - Diagnosis, treatment and prognosis of Leiomyosarcoma of the inferior vena cava. Eur $\mathbf{J}$ Surg 1996; 4:231-35.

25. MAURER G \& NANDA N - Two-dimensional echocardiographic identification of intracardiac leiomyomatosis. Am Heart J 1982; 103:915-17.

26. ROTTER AJ \& LUNDELL CJ - MR of intravenous leiomyomatosis of the uterus extending into the inferior vena cava. J Compt Assist Tomogr 1991; 15: 690-93. 
27. ANGERMEIER WK, ROSS JH, NOVICK AC et al. - Resection of nonrenal retroperitoneal tumor with large vena caval thrombi using cardiopulmonary bypass and hypothermic circulatory arrest. J Urol 1990; 144:735-9.

28. ROSENTHAL JT, COLONNA JO \& DRINKWATER DC - Leiomyosarcoma of the inferior vena cava with atrial extension: Long-term survival following resection and caval replacement with circulatory arrest. Urology 1995; 46: 876-78.
29. KASANO Y, TANIMURA H \& KUMADA K - Resectable leiomyosarcoma of the inferior vena cava extended into the right atrium with the use of cardiopulmonary bypass and graft replacement. Surgery 1995; 117:473-75.

30. MARSHALL FF, REITZ BA \& DIAMOND DA - A new technique for management of renal cell carcinoma involving the right atrium: hypothermia and cardiac arrest. J Urol 1984; 131:945.

31. COOPER NM, GUILLEM J, DALTON J et al. - Recurrent intravenous leiomyomatosis with cardiac extension. Ann Thorac Surg 1992; 53:139-41. 